\title{
Homologous tumor cell membrane vesicles active preferential self-recognition of tumor cells in vitro
}

Chenghu $\mathrm{Wu}^{2+}$, Ailin $\mathrm{Yu}^{3+}$, Yue Chen ${ }^{4}$ and Mingbo Fan ${ }^{1 *}$ (1)

\begin{abstract}
Cell membrane vesicles, as delivery carriers of drugs or biological agents in vivo, are an important therapeutic mode in the study of disease treatment. Tumor membrane-derived vesicles have been widely used in tumor therapy because of their good tumor enrichment effect. The most common method is the surface of nanoparticles coated with tumor cell membrane, which can effectively prolong the circulation time of particles in the blood and the enrichment of tumors. In this study, we prepared vesicles of different tumor cell membrane derivate and studied their targeting to tumors detailly. The results showed that homologous vesicles have high targeting to homologous tumor cells. The fluorescence of vesicles in homologous tumor cells was significantly higher than that in other tumor cells. This study will provide a new strategy and guidance for the clinical treatment of cancer based on the tumor cell membrane system.
\end{abstract}

Keywords: Tumor cell membrane, Self-recognition, Tumor-targeting, Tumor therapy, Homologous

\section{Graphical Abstract}

Tumor cells Tumor cells membrane vessicle

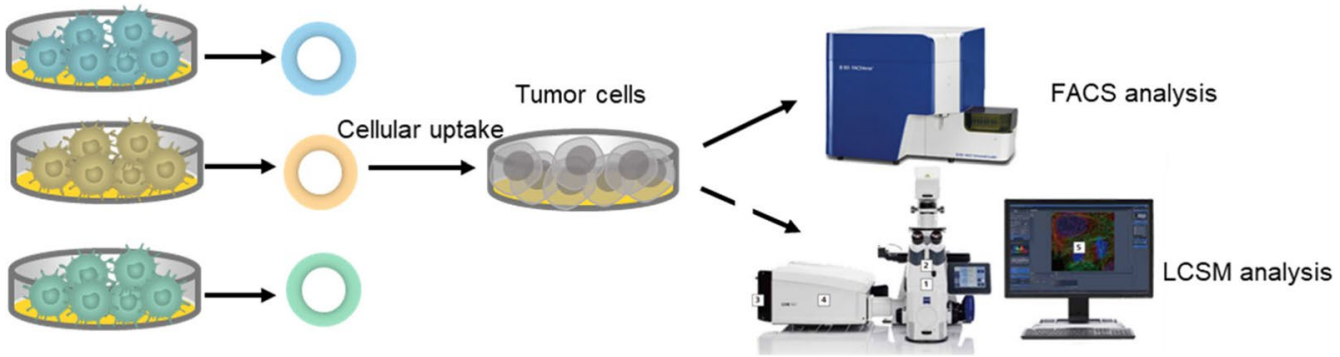

*Correspondence: wuchenghu010@163.com

${ }^{\dagger}$ Chenghu Wu and Ailin Yu contributed equally to this work

${ }^{1}$ Department of Neurosurgrey, The Central Hospital of Wuhan, Tongji

Medical College, Huazhong University of Science and Technology,

Wuhan 430014, China

Full list of author information is available at the end of the article

(c) The Author(s) 2022. Open Access This article is licensed under a Creative Commons Attribution 4.0 International License, which permits use, sharing, adaptation, distribution and reproduction in any medium or format, as long as you give appropriate credit to the original author(s) and the source, provide a link to the Creative Commons licence, and indicate if changes were made. The images or other third party material in this article are included in the article's Creative Commons licence, unless indicated otherwise in a credit line to the material. If material is not included in the article's Creative Commons licence and your intended use is not permitted by statutory regulation or exceeds the permitted use, you will need to obtain permission directly from the copyright holder. To view a copy of this licence, visit http://creativecommons.org/licenses/by/4.0/. 


\section{Introduction}

Tumor is still a huge killer that seriously affects public life and health, and there is still a lack of effective treatment at present [1]. Current treatments include surgery, chemotherapy, radiation therapy, and immunotherapy $[2,3]$. Chemotherapy is the first choice in the treatment of cancer, but its application in clinical treatment is limited due to its serious toxic and side effects [4]. Therefore, various methods have been developed to reduce the toxicity of drugs, among which the preparation of nanoparticles loaded chemotherapeutic drugs using nanotechnology can effectively reduce the toxic and side effects on normal tissues [5-7]. However, due to the lack of effective tumor targeting, chemotherapy drugs cannot be efficiently delivered to tumor cells, thus limiting the effect of tumor chemotherapy. Many researchers have proposed modifying tumor targeting antibodies on the surface of the particles to improve the uptake efficiency of tumor cells $[6,8]$. Such a research strategy can improve tumor targeting to a certain extent, but it is difficult to carry out on a large scale in clinical application due to the difficulties in tumor antigen identification, high antibody cost and difficulty in particle modification, etc. The idea of nanoparticles coated with cell membrane is expected to solve the above problems [9-11].

The surface of nanoparticles coated with the cell membrane was firstly proposed by Professor Liangfang Zhang. He firstly proposed in PNAS that the erythrocyte membrane coated on polymer nanoparticles could effectively prolong the circulation time of nanoparticles in the blood [12]. Since then, more and more researchers have found that many cell membranes have very different biological functions, which can be used to solve the difficulties in current research or application. Using tumor cell membrane to camouflage nanoparticles can not only prolong the circulation time of particles in the blood, but also improve the concentration of particles in the tumor and the uptake efficiency of tumor cells [13]. Some researchers extracted 4T1 breast cancer cell membrane and used it for nano-gel camouflages to deliver the chemotherapy drug of docetaxel, which effectively increased the concentration of chemotherapeutics in tumor cells and effectively inhibited the growth of tumor tissue, showing the advantage of tumor cell membrane in the delivery of antitumor drugs [14]. Additionally, it has been reported that nanoparticles coated with the B16F10 cell membrane can provide the antigen library on the tumor cell membrane to DC and stimulate the anti-tumor immune response [15]. There are many applications of such research, and many good results reveal the advantages of these cell membrane treatment system. However, the suitable selection in the numerous cell membranes, especially tumor cell membranes, has not been discussed in detail, and whether xenotumor cell membranes can be selected for the targeted delivery of anti-tumor drugs in vivo remains to be studied.

Here, we select several types of tumor cells that are most used in tumor cell membrane studies. We extracted tumor cell membranes and prepared nanoscale vesicles using a mature preparation process. We carefully investigated the tumor-targeting of cell membrane vesicles of different tumor cell origins at the cell level in vitro. Flow cytometry results showed that homologous tumor cells had the highest uptake efficiency of tumor cell membrane vesicles. The results of laser confocal detection also showed this phenomenon, and the fluorescence signal was strongest in homologous cells. This result was confirmed in three different tumor cell lines. Our study provides a basis for the tumor cell membrane antitumor therapy system. It is helpful to promote the application of tumor cell membrane system in clinical antitumor therapy.

\section{Experimental Materials}

1,1-Dioctadecyl-3,3,3,3-tetramethylindodicarbocyanine (DID) was purchased from Liuhe Biotech company (China). Liposome extruder was purchased from Avanti Polar lipids, Inc. (Yanyi BioTECH, China). 4',6-Diamidino-2-phenylindole (DAPI) (Sigma-Aldrich, St Louis, USA) was purchased from Xinri Biotech company and used according to the manufacturer's instructions. Dulbecco's Modified Eagle Medium (DMEM) was purchased from Huantai Inc. (Gibco, Grand Island, USA). Fetal bovine serum (FBS, ExCell Bio, Shanghai, China) was purchased from Huihong Biotech company. Fluoromount aqueous mounting medium (Sigma-Aldrich, St. Louis, USA) was purchased from Xinri Biotech company. Other reagents were purchased from Sangon and used as received.

\section{Cells culture}

B16-F10, 4T1 and Panc02 cells were obtained from Anhui Medical University. They were all cultured in DMEM supplemented with $10 \% \mathrm{FBS}$ in a $5 \% \mathrm{CO}_{2}$ humidified atmosphere at $37{ }^{\circ} \mathrm{C}$. The cells would be passaged when they reached $70-80 \%$ confluence in the medium. During the cell passages, the cells were digested with $0.25 \%$ trypsin for $2 \mathrm{~min}$ at $37{ }^{\circ} \mathrm{C}$ and resuspend in $10 \mathrm{~mL}$ PBS. Then the cells were centrifuged at $800 \mathrm{rpm}$ for $5 \mathrm{~min}$ to collect the cells for use.

\section{Tumor cell membrane vesicles (TCMVs) preparation and characterization}

For the TCMVs preparation: 10 million cells were frozen three times for the collection of cell lysate. Then, they 
were suspended into $500 \mu \mathrm{L}$ PBS. After centrifugation for $10 \mathrm{~min}$ at $400 \mathrm{~g}$, the cell membrane precipitation was collected. They were resuspended into $1 \mathrm{~mL}$ PBS for the vesicles preparation by the liposome extruder with the $200 \mathrm{~nm}$ filtration membrane. DID labelled vesicles were prepared by the addition of $0.5 \mu \mathrm{g}$ DID into the suspension for $0.5 \mathrm{~h}$ at room temperature.

The hydrodynamic diameter and zeta-potential of different TCMVs were detected by the dynamic light scattering of Malvern Instruments (Zetasizer Nano ZS90, UK). The diameters of TCMVs were monitored at predesigned time intervals to characterize the stability of vesicles. In addition, the morphology of the TCMVs were characterized by SEM (SU8010, HITACHI, Japan).

\section{Cells viability}

For the cytotoxic effect's examination of different TCMVs for the cells, $5 \times 10^{3}$ cells were seeded into the each well of 96-well plate and cultured overnight. $200 \mu \mathrm{g}$ TCMVs were incubated with the cells up to $72 \mathrm{~h}$. Then, the cells activity was examined by Cell Counting Kit- 8 (CCK8) assay with the absorption of $450 \mathrm{~nm}$ by the BioTek microplate reader.

\section{Cellular uptake in vitro}

For the flow cytometry (FCM) detection, the cells $\left(2 \times 10^{5}\right.$ cells/well $)$ were seeded into the 24 -well plates and cultured in the incubator of $37^{\circ} \mathrm{C}$ for $24 \mathrm{~h}$. The original medium of cells were removed with the instead of fresh culture medium containing DID-labeled TMCVs. The cells were incubated with the TMVCs for $2 \mathrm{~h}$. Then, the medium with DID-TMVCs was cleaned with PBS. The cells were collected with the treatment of trypsin for the FCM analyses by the CytoFLEX of Beckman Coulter.

For laser scanning confocal microscopy (LSCM) observation, the cells $\left(8 \times 10^{4}\right.$ cells/well $)$ were seeded into the 24-well plates which were covered with sterile round glass sheets. The cells were cultured overnight. Then, the DID-labeled TMCVs were added into the wells and incubated with the different cells for $2 \mathrm{~h}$. The culture medium of cells was replaced with PBS and rinsed for three times. $1 \mathrm{~mL}$ of $4 \%$ formaldehyde was placed into the 24-well plates to fix the cells for $30 \mathrm{~min}$. After rinsed three times with PBS, the cells were stained with DAPI for $5 \mathrm{~min}$. Then, they were washed with PBS for three times to remove excess DAPI. Fluoromount aqueous mounting medium was used to protect the fluorescence from being quenched. The cellular uptake of TMVCs was observed by LSCM (LSM 710, Carl Zeiss Inc., Jena, Germany).

\section{Statistical analysis}

All the experiments data are expressed as mean \pm S.D. unless otherwise noted. Significance levels were defined as ns (not significant, $\mathrm{P}>0.05$ ), $\quad{ }^{*} \mathrm{P}<0.05, \quad{ }^{* *} \mathrm{P}<0.01$, **: $\mathrm{P}<0.001$, and ${ }^{* * * * \mathrm{P}}<0.0001, \mathrm{P}$ values were calculated by Prism 7 software.

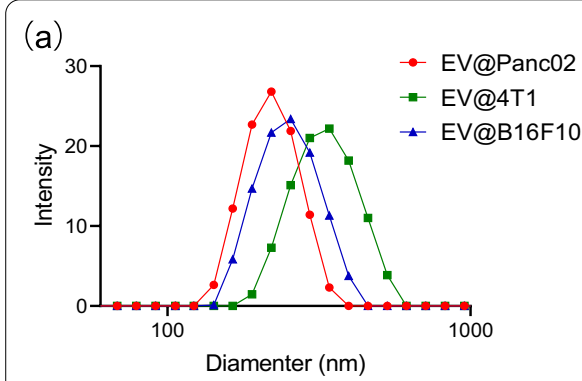

(d)

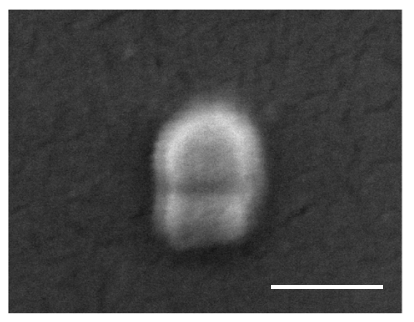

EV@Panc02
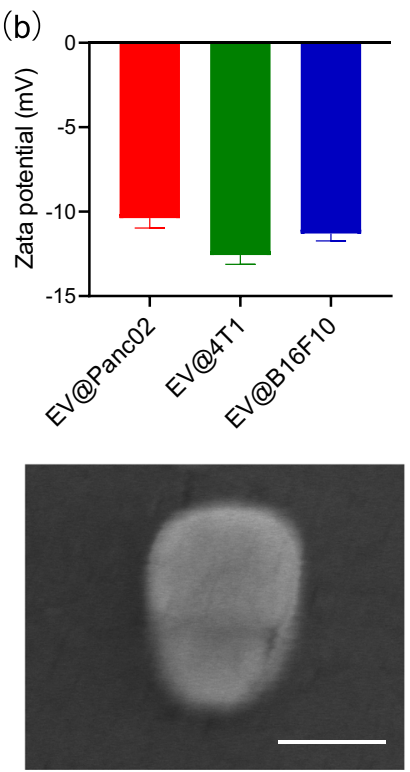

EV@4T1
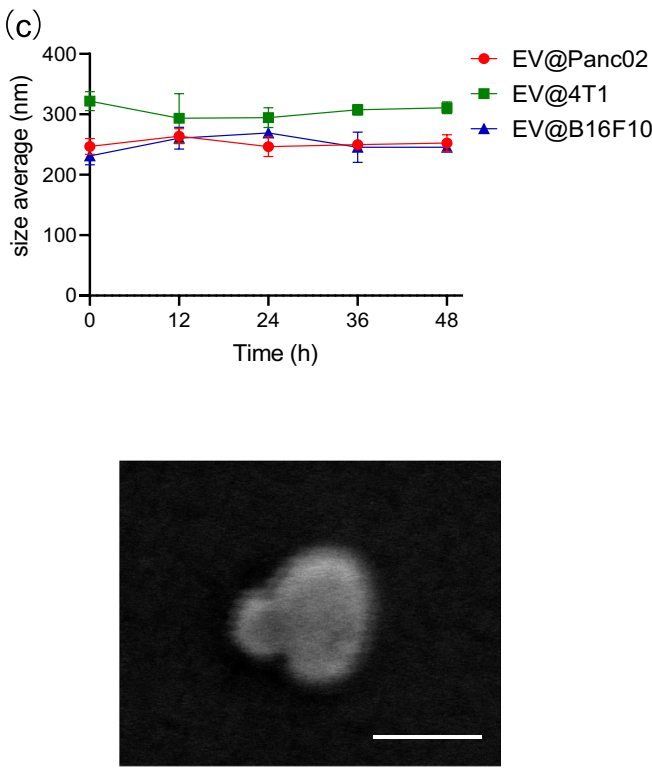

EV@B16F10

Fig. 1 Hydrodynamic diameters (a), surface zeta potential (b), and the stability of TCMVs (c) detected by the dynamic light scattering. d SEM images of TCMVs 


\section{Results and discussion}

Characterization of tumor cell membrane vesicles (TCMVs)

Tumor cell-membrane-derived vesicles have been widely used for drug delivery in vivo to treat tumors because of their good tumor targeting. The vesicles with good dispersion can be obtained by conventional membrane separation and liposome extrusion. Here, we prepared three different tumor-derived cell membrane vesicles. As the results shown in Fig. 1a, the hydrodynamic diameters of TCMVs from Panc02, 4T1 and B16-F10 arranged from 250 to $320 \mathrm{~nm}$. Meanwhile, we measured the surface zeta potential of these vesicles. The zeta potential of all vesicles were around $-10 \mathrm{mV}$ (Fig. 1b). The results were consistent with the negative potential of cell membranes reported by others. We further investigated the stability of the artificially prepared TCMVs, we suspended the vesicles into the PBS of $\mathrm{pH} 7.4$ with $10 \%$ FBS and performed the detection of diameters at different time points. The results in Fig. 1c demonstrated the tumor cell-membrane-derived vesicles exhibit good stability at least for $48 \mathrm{~h}$. As an in vivo delivery system, good stability can guarantee the success rate of drug delivery in vivo. To further observe the shape of the vesicles, scanning electron microscopy (SEM) was used to characterize its morphology. The vesicles presented the spherical structure with slight thick outer membrane at the margin (Fig. 1d).
Cytotoxicity of tumor cell membrane vesicles (TCMVs)

As a vector of drug delivery in vivo, the non-toxicity or low toxicity of TCMVs was the essential characteristics. Here, we selected the 4T1, Panc02 and B16-F10 cells, which were incubated with EV@Panc02, EV@4T1 and EV@B16-F10 respectively. After 24 h, the survival of different cells were analyzed by the CCK8. As the results shown in Fig. 2a, b, the survival rate of all the cells treated with vesicles was more than $90 \%$, and there was no significant decrease in survival rate with the extension of time. These results suggested that the tumor membranederived vesicles were not toxic to the various tumor cells. However, vesicles can be captured by any cells in vivo, the cell status can be a guide for TCMVs as delivery vehicles in vivo. So we chose a type of nerve cell, PC12 cells, one of the most important cells in the body, for the detection whether tumor membrane-derived vesicles affect PC12 survival. From the results in Fig. 2d, the survival rate of PC12 cells treated with different vesicles was higher than $90 \%$ within $60 \mathrm{~h}$. The survival rate decreased only at a longer time point of $72 \mathrm{~h}$, but it was also higher than $85 \%$. These results suggested that TCMVs can be used as safe in vivo delivery vectors without causing damage to cells.

\section{Targeting of tumor cell membrane vesicles (TCMVs) to tumor cells}

In order to further clarify the targeting ability of TCMVs to the various tumor cells, we labeled the TCMVs with
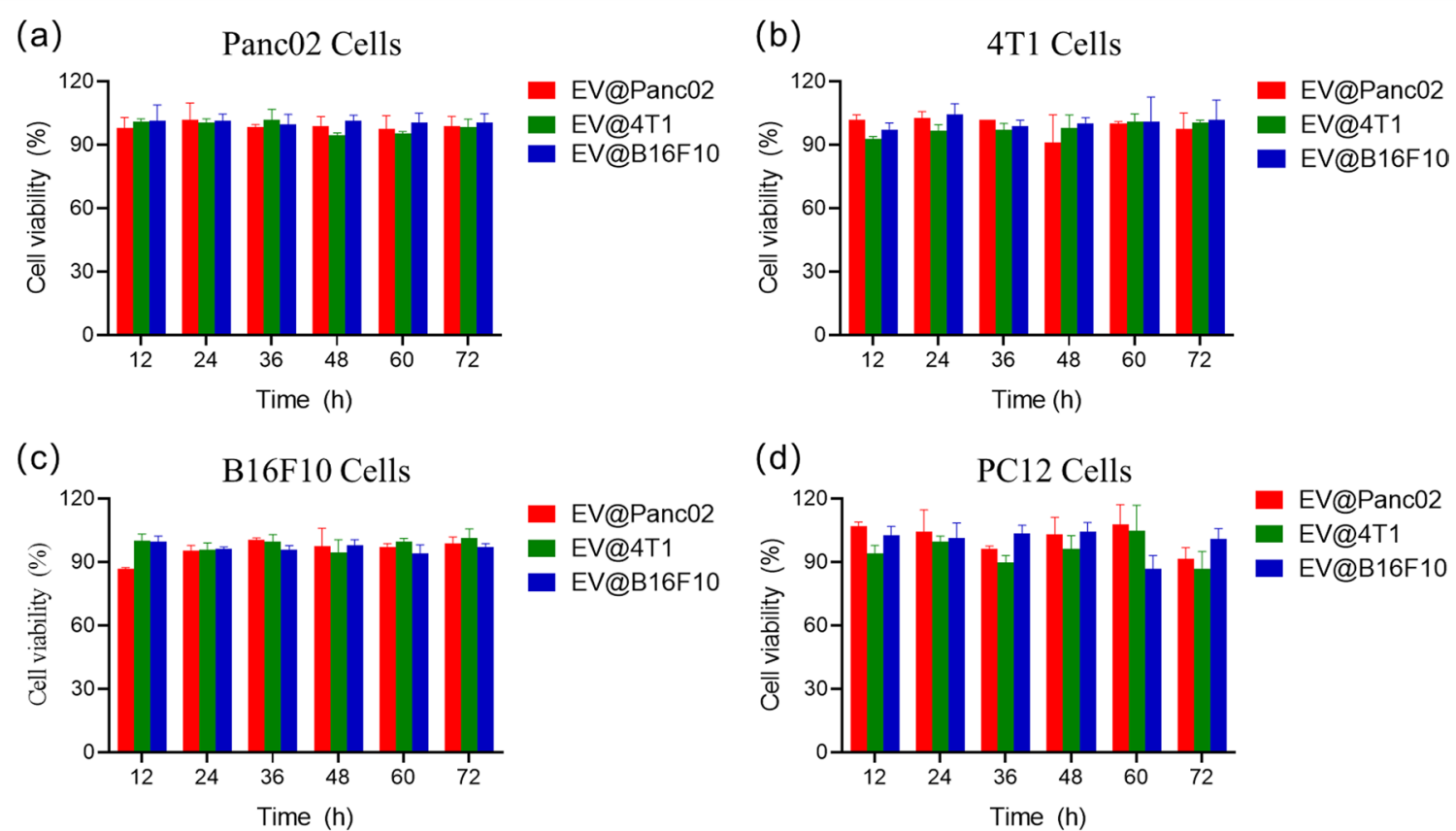

Fig. 2 Cytotoxicity of tumor membrane-derived vesicles (EV@Panc02,EV@4T1 and EV@ B16-F10) to the Panc02 (a),4T1 (b), B16-F10 (c) and PC12 cells $(\mathbf{d})$ 


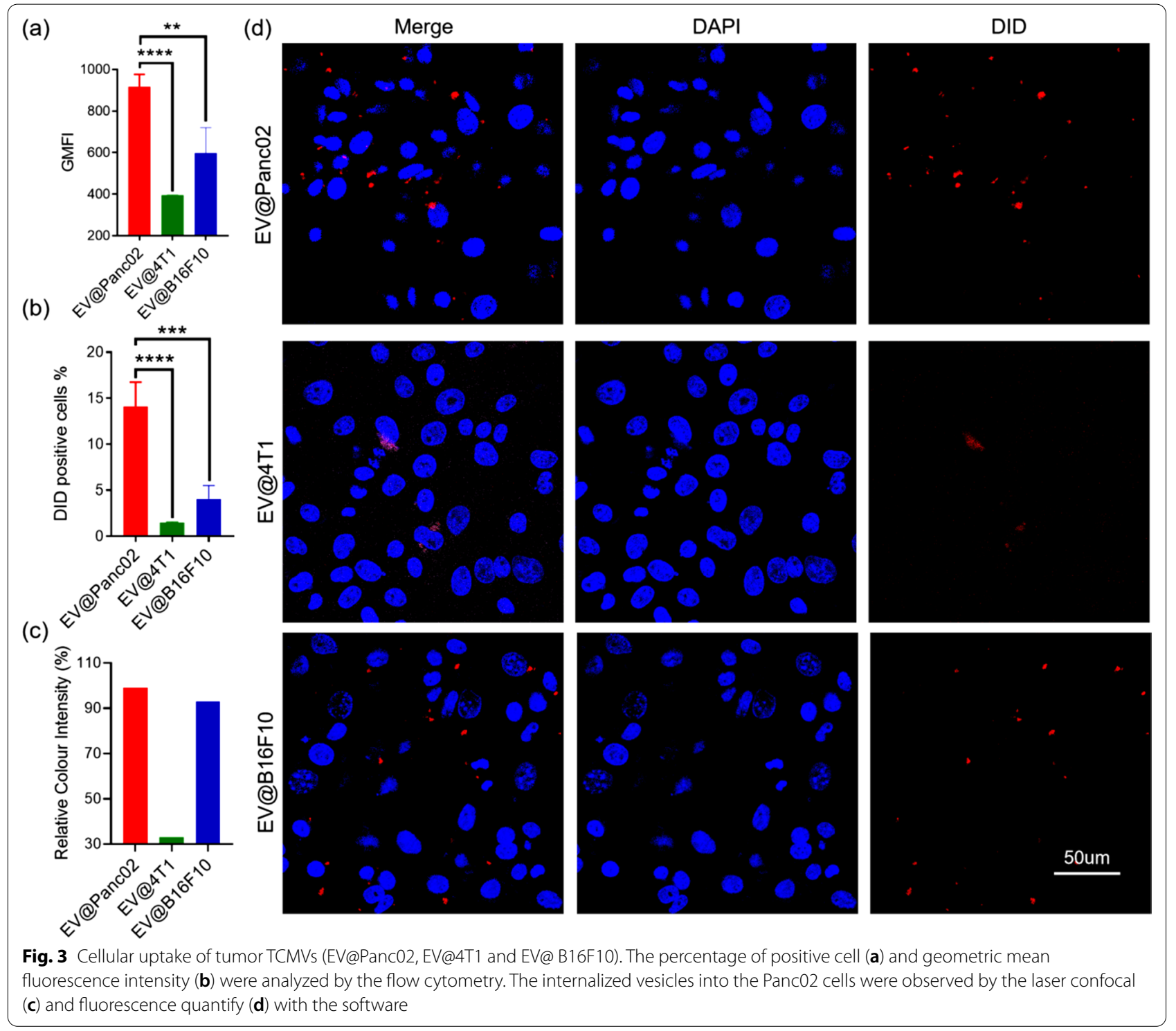

DID dye. Then the TCMVs were incubated with different tumor cells. Flow cytometry and scanning laser confocal scanning were used to detect the cellular uptake of vesicles from different tumor cell membranes, so as to evaluate the targeting of different vesicles to the tumors. For the Panc02 cells treated with EV@Panc02, EV@4T1 and EV@B16-F10 respectively, it could be seen that the DID positive panc02 cells treated with EV@Panc02 were much more than the other vesicles (Fig. 3a). The statistic fluorescence also indicated that Panc02 cells internalized much more EV@Panc02 (Fig. 3b). To further confirm the results of flow cytometry, we incubated the Panc02 cells with DID-TCMVs for $2 \mathrm{~h}$ to be observed under the laser confocal. Results in Fig. 3c shown that the red fluorescence of vesicles in EV@Panc02 group were much higher than the other groups. In order to quantify the experimental results as much as possible to facilitate the explanation of the targeting, we used software to quantify the red fluorescence intensity. The results supported the above experimental conclusions and demonstrated that the vesicles derived from Panc02 cell membranes had the highest targeting ability to Panc02 cells (Fig. 3d).

To estimate whether the vesicles from other tumors can target homologous tumors, the 4T1 and B16F10 cells were treated with EV@Panc02, EV@4T1 and EV@B16F10 respectively. The results of flow cytometry and laser confocal demonstrated that 4T1 tumor cells have higher uptake efficiency for homologous $4 \mathrm{~T} 1$ tumor vesicles. The fluorescence of DID-EV@4T1 was stronger in 4T1 cells than other cells (Fig. 4). The similar 


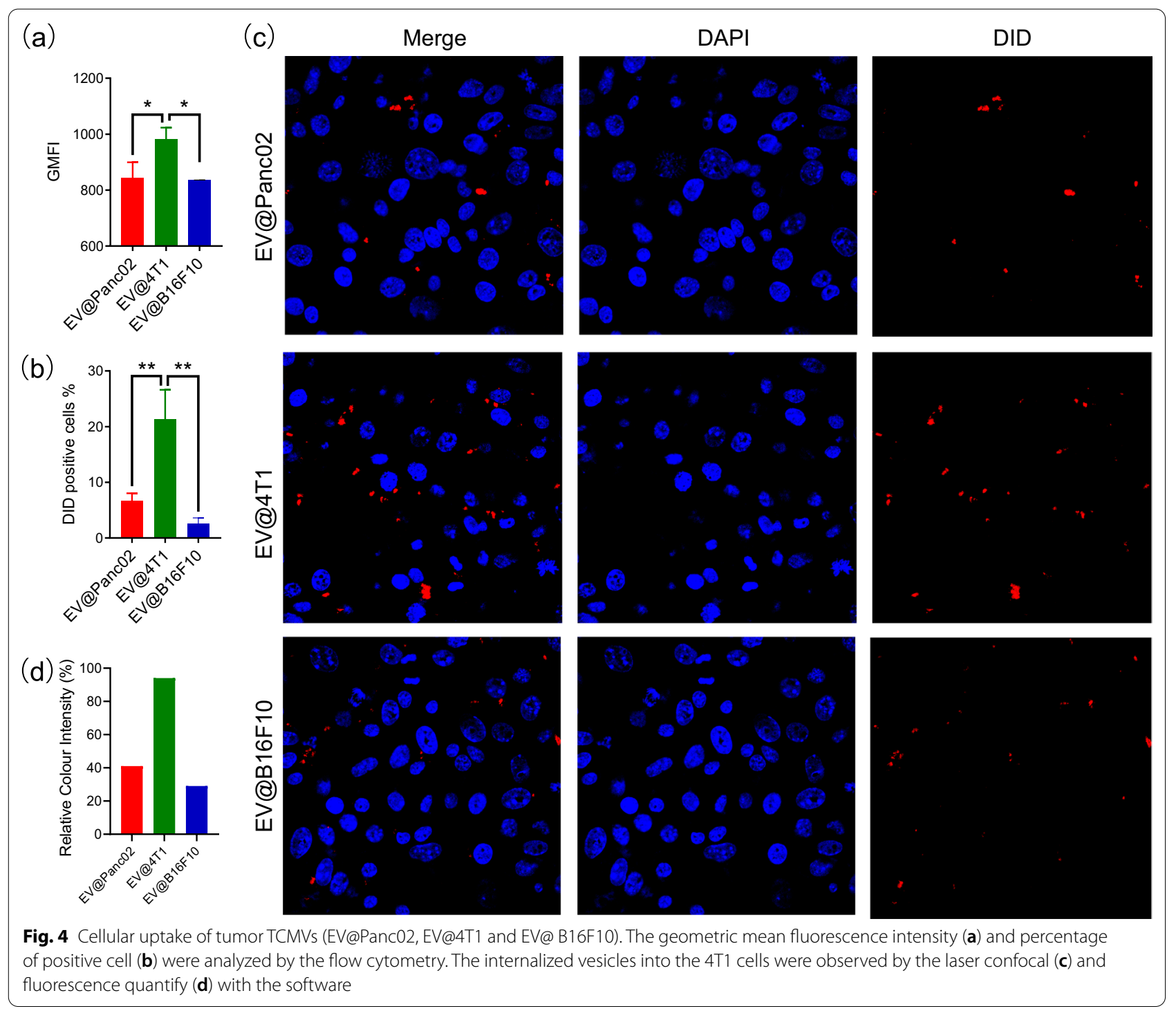

phenomenon were also found in the B16F10 cells (Fig. 5). Bias in uptake of different vesicles by tumor cells confirm differences in vesicle targeting. Therefore, homologous tumor cell membrane derived vesicles are more likely to be internalized by homologous tumor cells and can be used as effective drug delivery vectors in vivo.

Here, we try to identify the mechanisms by which homologous tumor membranes are highly targeted to homologous cells through the literature. Tumor cells are highly active cells in nature, which can proliferate and secrete constantly. They can recognize and transmit information between tumor cells through a powerful information network. We think sugar chain molecules on the surface of the tumor cells were the main functional element, they play an important role in the process of cognate tumor targeting. The function of the sugar chain molecules mainly is to promote information identification and communication between the cells and tumor cells. Due to its own genome disorder, a lot of sugar chain molecules were expressed on the surface of tumor cells, so as to maintain its own survival. We could successfully extract tumor cell membranes, which retain intact protein components on the cell surface, including glycoproteins. So, when the tumor cell recognizes the TCMVs, it could ingest them to recycle the sugar chain molecules, and we think this might be why the tumor cell membrane is able to target homologous tumor cells. Of course, the specific mechanism needs further experimental verification. 


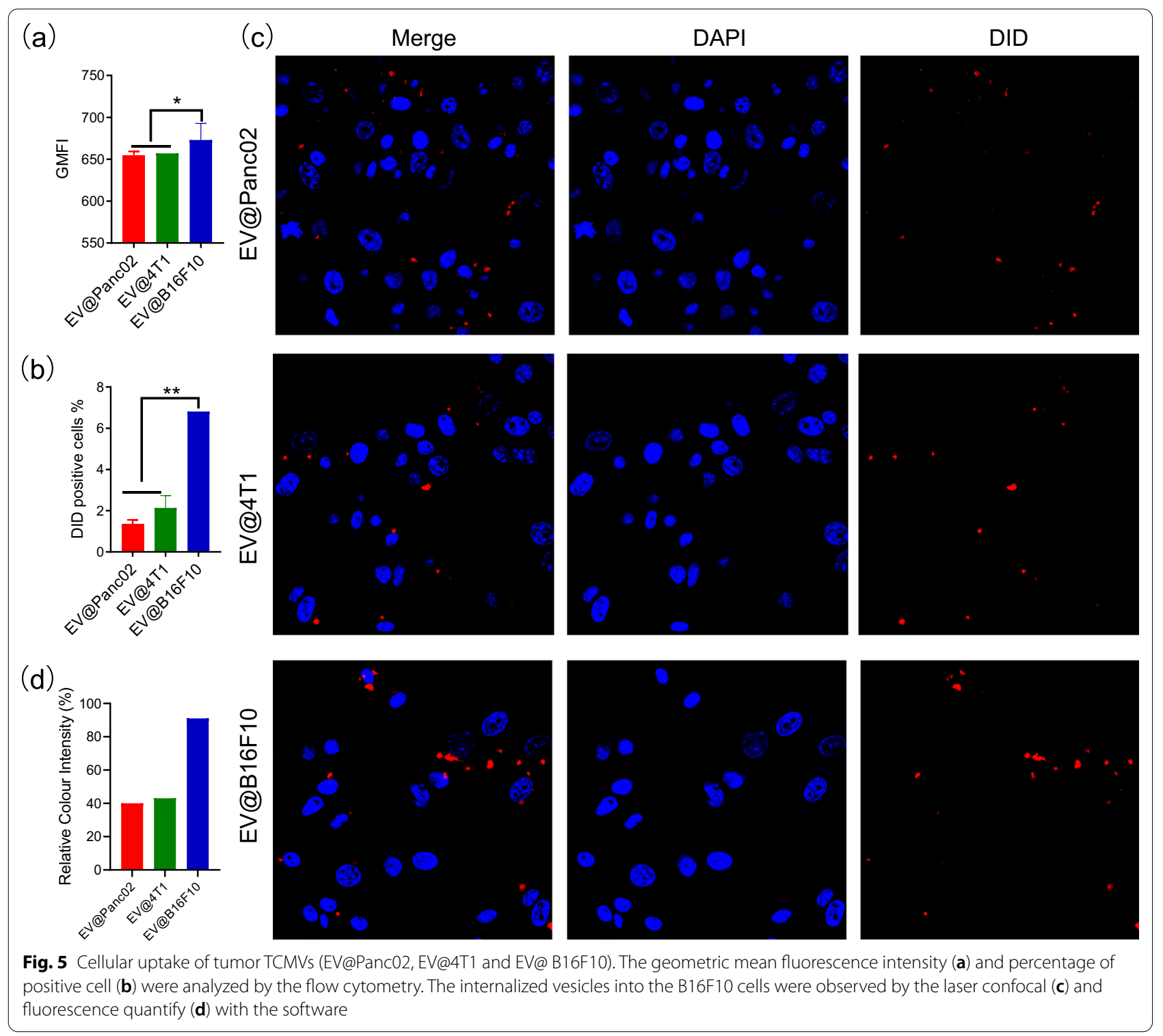

\section{Acknowledgements}

Not applicable.

\section{Authors' contributions}

CHW, ALY and MBF conceived the study and carried out the research; YC drafted the manuscript; MBF participated in the design of the manuscript; all authors participated in revision of the manuscript and figure. All authors read and approved the final manuscript.

\section{Funding}

Not applicable.

\section{Availability of data and materials}

All data produced during the current study are available from the corresponding author on reasonable request.

\section{Declarations}

\section{Ethics approval and consent to participate}

Research experiments conducted in this article with animals or humans were approved by the Ethical Committee and responsible authorities of our research organization(s) following all guidelines, regulations, legal, and ethical standards as required for humans or animals.

\section{Consent for publication}

All authors contributed to this work presented in this manuscript. All authors have given approval for the final version of the manuscript.

\section{Competing interests}

On behalf of all authors, the corresponding author states that there is no conflict of interest.

\section{Author details}

${ }^{1}$ Department of Neurosurgrey, The Central Hospital of Wuhan, Tongji Medical

College, Huazhong University of Science and Technology, Wuhan 430014, China. ${ }^{2}$ School of Mathematics and Computer Science, Wuhan Polytechnic 
University, Wuhan 430048, China. ${ }^{3}$ Department of Endocrinology, Renmin Hospital of Wuhan University, Wuhan 430060, China. ${ }^{4}$ School of Clinical Medicine, Anhui Medical University, Hefei 230000, China.

Received: 28 September 2021 Accepted: 2 January 2022

Published online: 10 January 2022

\section{References}

1. Tan S, Li D, Zhu X (2020) Cancer immunotherapy: pros, cons and beyond. Biomed Pharmacother 124:109821

2. Roy P, Saikia BJ (2016) Cancer and cure: a critical analysis. Indian J Cancer 53(3):441

3. Mahmood J, Shukla HD, Soman S et al (2018) Immunotherapy, radiotherapy, and hyperthermia: a combined therapeutic approach in pancreatic cancer treatment. Cancers 10(12):469

4. Schirrmacher VJ (2019) From chemotherapy to biological therapy: a review of novel concepts to reduce the side effects of systemic cancer treatment. Int J Oncol 54(2):407-419

5. Zhao CY, Cheng R, Yang Z, Tian ZM (2018) Nanotechnology for cancer therapy based on chemotherapy. Molecules 23(4):826

6. Cheng $\mathrm{H}$, Jiang $X Y$, Zheng RR et al (2019) A biomimetic cascade nanoreactor for tumor targeted starvation therapy-amplified chemotherapy. Biomaterials 195:75-85

7. Liang X-J, Chen C, Zhao Y, Wang PC (2010) Circumventing tumor resistance to chemotherapy by nanotechnology. In: Zhou J (ed) Multi-drug resistance in cancer. Springer, Berlin, pp 467-488

8. Glasgow MD, Chougule MB (2015) Recent developments in active tumor targeted multifunctional nanoparticles for combination chemotherapy in cancer treatment and imaging. J Biomed Nanotechnol 11(11):1859-1898

9. Qiu W-X, Zhang M-K, Liu L-H et al (2018) A self-delivery membrane system for enhanced anti-tumor therapy. Biomaterials 161:81-94

10. Lv P, Liu X, Chen X et al (2019) Genetically engineered cell membrane nanovesicles for oncolytic adenovirus delivery: a versatile platform for cancer virotherapy. Nano Lett 19(5):2993-3001

11. Zhang Y, Cai K, Li C et al (2018) Macrophage-membrane-coated nanoparticles for tumor-targeted chemotherapy. Nano Lett 18(3):1908-1915

12. Hu C-MJ, Zhang L, Aryal S, Cheung C, Fang RH, Zhang L (2011) Erythrocyte membrane-camouflaged polymeric nanoparticles as a biomimetic delivery platform. Proc Nat Acad Sci 108(27):10980-10985

13. Zhang W, Yu M, Xi Z et al (2019) Cancer cell membrane-camouflaged nanorods with endoplasmic reticulum targeting for improved antitumor therapy. ACS Appl Mater Interfaces 11(50):46614-46625

14. Barui AK, Oh JY, Jana B, Kim C, Ryu JH (2020) Cancer-targeted nanomedicine: overcoming the barrier of the protein corona. Adv Ther 3(1):1900124

15. Raza F, Zafar H, Zhang S et al (2021) Recent advances in cell membranederived biomimetic nanotechnology for cancer immunotherapy. Adv Healthc Mater 10(6):2002081

\section{Publisher's Note}

Springer Nature remains neutral with regard to jurisdictional claims in published maps and institutional affiliations.

\section{Submit your manuscript to a SpringerOpen ${ }^{\circ}$ journal and benefit from:}

- Convenient online submission

- Rigorous peer review

- Open access: articles freely available online

- High visibility within the field

- Retaining the copyright to your article

Submit your next manuscript at $\boldsymbol{\nabla}$ springeropen.com 